\title{
A Study on real-time Flood Monitoring System based on Sensors using Flood Damage Insurance Map
}

\author{
S. Yeon ${ }^{1}$, J. Kang ${ }^{1 *}$, I. Lee $^{1}$ \\ ${ }^{1}$ Spatial Information Research Institute, Korea Land And Geospatial InformatiX Corporation, (yeon, kangdaejang, les05)@1x.or.kr
}

Commission VI, WG VI/4

KEY WORDS: Monitoring System, Flood Damage, Insurance Map, IoT(Internet of Things), LPWA(Low Power Wide Area)

\begin{abstract}
:
Typical types of natural disasters that occur in Korea are damages from heavy rain, storm, and heavy snow. In order to prepare for this, the storm and flood damage insurance program is operated. For this purpose, the risk of these damages is calculated for each region, and the storm and flood damage insurance map is created based on the risk. This map can provide insight into the degree of risk to wind and flood, snow damage, as well as policies to prevent and prepare for each type of natural disaster. In order to support decision-making by utilizing this insurance map, it is necessary to use with Storm and Flood Damage Information contents. In order to efficiently construct such disaster information contents, it is possible to utilize public data produced by various organizations. Korea has a public data portal to open various administrative information. The public data portal currently publishes and updates about 25,000 data from 700 organizations. In this study, the linkage system is designed that can construct disaster information contents by collecting public data and processing it so that it can be overlapped with the insurance map. The system automatically links public data to keep up-to-date disaster information content. It is expected that it will be able to prevent and prepare for natural disaster by supporting the decision making of decision makers related to flood damage.
\end{abstract}

\section{INTRODUCTION}

Natural disasters are caused by meteorological factors or ground movements and are difficult to predict and the scale of damage is enormous. In order to mitigate the damage of natural disasters, it is necessary to classify the hazardous areas by each disaster factor and monitor them in real time. With the recent development of IoT technology, practical applications have been spreading with IoT technology in many industries. IoT technology is a technology that can be controlled from the outside by connecting the Internet to an object, and is suitable for real-time monitoring of the change in the state of nature.

Therefore, this study suggests a way to identify the change of river level status in real time.

For this, a device was built that could check the immersion information and deliver multi-sensor information by combining sensor technology and communication technologies for remote sensing.

A simple management prototype program was developed, designed with an interface protocol that complies with the oneM2M standard. Various communication standards for IoT services are currently being mixed up through various associated agencies. To accommodate large amounts of data with different sources at once, appropriate communication interfaces as well as system resources need to be applied, and algorithms to handle them smoothly should be applied. Thus, after discussing the application of the algorithm, it was proposed to link it with the Storm and Flood Damage Insurance Map to increase its usability.

\section{METHOD OF FLOOD DETECTION}

\subsection{Use flood damage insurance map}

Currently, many local governments in South Korea are considering various ways to prevent floods. In response to the flood damage, 227 local governments make a Storm and Flood Damage Insurance Map that reflects the characteristics of disasters by region. The hazards covered by the flood insurance coverage are typhoon, flood, storm, wind, wave, tsunami, snow, earthquake, and, depending on classification criteria, can be classified as flood, wind, and snow damage (excluding earthquake hazards). The flood damages include typhoons, heavy rains, floods and tsunamis, and each one is reflected on the Storm and Flood Damage Insurance Map through risk analysis. The river and inland flood risk, wind hazard, snow hazard risks are calculated for the hazard risks. And with the GIS grid calculation, the total risk map and insurance premium rate map is made. Table 1 show the river and inland flood hazard risk weight.

\begin{tabular}{|l|l|l|}
\hline Flooding depth $(\mathrm{m})$ & \multicolumn{1}{|c|}{ Grade } & \multicolumn{1}{c|}{ Phase } \\
\hline $0-0.5$ & 1 & safe \\
\hline $0.5-1.0$ & 2 & danger \\
\hline $1.0-.20$ & 3 & very danger \\
\hline
\end{tabular}

Table 1.show the flood hazard risk weight

\subsection{Sensing device making}

The flooding information notification device consists of various sensors. In particular, we focused on durability such as power management and waterproofing so that we can monitor more than two years without the need of permanent power supply. The sensor device configuration is shown in Table 2. Each sensor constituting the sensor device used a general purpose product which is cost competitive according to the function.

\begin{tabular}{l|l|l} 
Kind & Purpose & Product Name \\
\hline
\end{tabular}

\footnotetext{
* Corresponding author
} 


\begin{tabular}{|l|l|l|}
\hline Acceleration & $\begin{array}{l}\text { Triaxial sensor Measure } \\
\text { theacceleationofgravity }\end{array}$ & $\begin{array}{l}\text { BMA250E/BOSH } \\
\text { E }\end{array}$ \\
\hline Tilt Sensor & electricityusecontrol fortiltsensor & SQ-MIN-200 \\
\hline Level Sensor & water level detection & \\
\hline $\begin{array}{l}\text { Network } \\
\text { Module }\end{array}$ & LoRa, NB-IoT & SoluM, Huawei \\
\hline
\end{tabular}

Table 2. Sensor List of sample device

The flood information notification device should be able to observe the rapidly changing water level in the valley type stream. Power management is also needed to provide long-term river flood monitoring. For this, methods to minimize power consumed were studied to maximize service life. This is the reason for the utilization of the tilt sensor, and the role of the device to be put into the active state in a wake-up position when it usually exceeds the set reference level.

\section{MONITORING SYSTEM}

\subsection{Requirements list}

In order to remotely monitor flood, secure network reliability to enable interconnection even in the worst possible conditions, such as shadow areas and bad weather. (Network reliability assurance) Periodic status checking messages should be exchanged to monitor the normal operation of the flood information notification device. Figure 3 show component of the prototype system for monitoring.

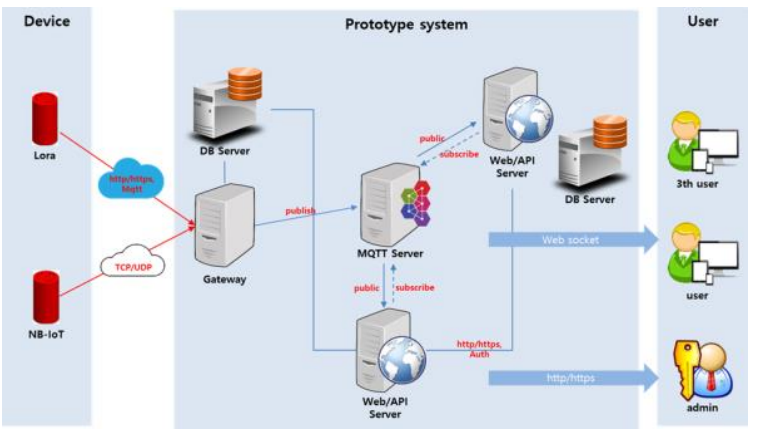

Figure 2. Monitoring System Component

\subsection{Utilization of LPWA network}

Sensor information communication methods are Lo Ra (Long Range) and NB- IoT (Narrowband) technologies, and the communication coverage can be sufficiently secured through the private network of the domestic mobile communication companies. This allows the status information of the river level to be checked without repeaters such as AP (Access Point) equipment, and can be used for early warning of river floods such as evacuation notice when the threshold value is exceeded.

\begin{tabular}{|l|l|l|}
\hline Network & NB-IoT & LoRa \\
\hline bandwidth & $200 \mathrm{kHz}$ & $125 \mathrm{kHz}$ \\
\hline $\begin{array}{l}\text { maximum speed } \\
\text { (uplink/downlink }\end{array}$ & $27.2 / 62.5 \mathrm{kbps}$ & $5.47 \mathrm{kbps}$ \\
\hline radio frequency & $698 \sim 960 \mathrm{Mhz}$ & $920 \mathrm{Mhz}$ \\
\hline urban coverage & $2.1 \mathrm{~km}$ & $1.8 \mathrm{~km}$ \\
\hline suburbs & $\sim 13 \mathrm{~km}$ & $\sim 12 \mathrm{~km}$ \\
\hline
\end{tabular}

\begin{tabular}{|l|l|l|}
\hline \begin{tabular}{l} 
number $\begin{array}{l}\text { terminal } \\
\text { (per cell) }\end{array}$ \\
\hline $\begin{array}{l}\text { battery life } \\
\text { (data } \\
\text { transmission once } \\
\text { a day }\end{array}$
\end{tabular} & $200 \sim 4,000$ \\
\hline $\begin{array}{l}\text { network } \\
\text { construction }\end{array}$ & $\begin{array}{l}\text { LTenerted by existing } \\
\text { LTE networks }\end{array}$ & new installation \\
\hline feature & $\begin{array}{l}\text { supports 3GPP } \\
\text { Rel.13 NB-IoT air } \\
\text { interfaces and } \\
\text { protocols }\end{array}$ & $\begin{array}{l}\text { wireless } \\
\text { communication } \\
\text { based on LoRa } \\
\text { Technology }\end{array}$ \\
\hline
\end{tabular}

Table 3. LPWA technology comparison

\subsection{Result of experiment}

First, the feasibility of constructing an intelligent monitoring system to manage facilities by using effective sensors was tested. With the IoT device on standby, the battery maximizing technology was improved by detecting a slight eternal pressure and adding the ON/OFF function to allow the user to adjust the battery status in activated mode and provide power when needed.

Second is securing the IoT platform technology linked to mobile carrier networks Telecom companies expanded to further extend the practical use of IoT. According to the previous year's LoRa of SK Telecom, this study expanded the communication range by applying NB-IoT through the technical agreement with LG U+.

Third, through the application of the improved sensor devices, external appearances of a terminal that may include various sensors, batteries, and communication modules which can detect tilt, vibration, location, depth of water, etc. were manufactured in accordance with the regulations of the law.

Fourth, flooding information was collected and analyzed. The information transmitted from the sensor terminal was gathered and applied in visualizing the analyzed data together with the information collection and integrated monitoring (Web/Mobile) technology, integrated controller based status information and analysis, and predictive monitoring technology. The modeling technology was also applied to integrate sensor and structure information for visualization.

\section{CONCLUSION}

The study proposed sensor devices to detect river flooding in areas with a high risk of flooding. If the device is deployed in danger area according to the classification criteria by the Storm and Flood Damage Insurance Map and monitored in real time, human and material damage will be reduced by detecting and responding to the flood early. This study is expected to contribute to finding new ways to utilize the Storm and Flood Damage Insurance Management System that will be open to the private sector in 2018 .

\section{ACKNOWLEDGEMENTS}

This research was supported by a grant [MOIS-DP-2013-62] through the Disaster and Safety Management Institute funded by Ministry of the Interior and Safety of Korean government. 


\section{REFERENCES}

Lee, J.S., Lee, I.S., 2015. A Study on Storm and Flood

Damage Insurance Management Map Production. LXSIRI

Report 18, Spatial Information Research Institute,

Jeollabuk-do, Korea.

Lee, J.S., Lee, I.S., 2017. Automation Modelling of the

Storm and Flood Hazard Risks for Insurance Premium Rate

Map. Journal of the Korean Cadastre Information Association, 19(2), pp. 3-13. 